\title{
ADSORPTION OF HYDROGEN SULFIDE USING PALM SHELL ACTIVATED CARBON: AN OPTIMIZATION STUDY USING STATISTICAL ANALYSIS
}

\author{
Lee Chung Lau', NorhusnaMohamadNor ${ }^{2}$, Abdul Rahman Mohamed ${ }^{3}$, KeatTeong Lee ${ }^{4}$ \\ ${ }^{1,2,3}$ School of Chemical Engineering, UniversitiSains Malaysia, Engineering Campus, Seri Ampangan, 14300 \\ NibongTebal, Pulau Pinang, Malaysia., Tel.: +604-5996467; Fax: +6045941013 \\ chktlee@eng.usm.my
}

\begin{abstract}
Removing $\mathrm{H}_{2} \mathrm{~S}$ from biogas that is produced from anaerobic digestion of palm oil mill effluent is a crucial step in order for the biogas to be utilized as a source of energy. In this study, palm shell activated carbon (PSAC) prepared by steam activation was used to adsorb $\mathrm{H}_{2} \mathrm{~S}$ from simulated biogas. The parameters studied were $\mathrm{H}_{2} \mathrm{~S}$ concentration, adsorption temperature and space velocity. The effect of these parameters towards breakthrough adsorption capacity was studied using statistical analysis with Design Expert Software. $\mathrm{H}_{2} \mathrm{~S}$ concentration and space velocity were found to be significant in affecting the breakthrough adsorption capacity.Adsorption temperature on its own was found not to have significant effect on the breakthrough adsorption capacity but its interaction with other parameters was found to be significant. Characterization of fresh and spent PSAC confirmed and provided further information on the adsorption of sulfur species on PSAC pore surface.
\end{abstract}

Keywords: Activated carbon; Biogas; Hydrogen sulfide; Adsorption

\section{INTRODUCTION}

Palm oil mill effluent (POME) is the pollutant generated from the oil palm industries in Malaysia and must be treated before discharge. One of the possible way to treat POME is by subjecting it to anaerobic digestion that produces biogas. Biogas can be combusted directly as fuel. $\mathrm{Ng}$ et al. reported that 1,688 million $\mathrm{m}^{3}$ of biogas is generated from palm oil mill in 2009 [1]. Biogas concentration largely varies from 13.5$49.0 \%$ methane $\left(\mathrm{CH}_{4}\right)$ and the remaining carbon dioxide $\left(\mathrm{CO}_{2}\right)$ [2]. Typically, trace amount of hydrogen sulfide $\left(\mathrm{H}_{2} \mathrm{~S}\right)$ between $0-1 \%$ is also produced in biogasas a result from the anaerobic digestion of POME [3]. Biogas should not be emitted directly to the atmosphere because $\mathrm{H}_{2} \mathrm{~S}$ is corrosive and $\mathrm{CH}_{4}$ is a greenhouse gas. Instead, biogas can be utilized as a source of energy by combusting biogas in a gas engine to generate electricity or steam. However, $\mathrm{H}_{2} \mathrm{~S}$ must be removed prior to combustion or it can cause severe corrosion [4].For biogas scrubbing technology, $\mathrm{H}_{2} \mathrm{~S}$ adsorption with activated carbon appears to be a promising method. Activated carbon is a cheap adsorbent that is widely utilized in air pollution abatementtechnology due to favorable surface propertiesthat allows it to have high adsorption capacity and fast reaction kinetic even at ambient temperature. Activated carbon can be produced from various lignocellulosic biomass such as coconut shell, corncob and palm shell. The use of palm shell to synthesize activated carbon for $\mathrm{H}_{2}$ Sremoval is more economical because both palm shell and $\mathrm{H}_{2} \mathrm{~S}$ are by-products from the oil palm industries. Thus, the use of palm shell activated carbon (PSAC) is a sustainable process because a waste from the oil palm industry is utilized to remove acidic gas generated within the same industry. PSAC is conventionally prepared using a two-step process; carbonization and activation. During carbonization, volatile compound in palm shell will be removed in the inert atmosphere. Carbon is retained due to the absence of oxygen that avoids the formation of carbon dioxide. The product after carbonization process is palm shell char that contains mostly carbon material with a surface area of about $100 \mathrm{~m}^{2} / \mathrm{g}$. After that, the char will be activated using steam or carbon dioxide. Thermal treatment using steam or carbon dioxide will distort the structure of char to form porous carbon that has high surface area and good adsorption capability.

In this research, several reaction parameters; $\mathrm{H} 2 \mathrm{~S}$ concentration, adsorption temperature and space velocity that affect breakthrough adsorption capacity using steam activated PSAC were studied. These parameters were studied using statistical analysis by employing Software Design Expert 6.0. Design of experiment is generated by the software in order to minimize the amount of experiments required to study the parameters thoroughly. In addition, the importance of each parameter in affecting activated carbon adsorption capacity can be identified. Interaction between reaction parameters can 
be also analyzed so that detailed understanding between $\mathrm{H} 2 \mathrm{~S}$ adsorption capacity and reaction parameters can be obtained.

\section{EXPERIMENTAL}

\subsection{Chemicals}

Steam activated PSAC used in this study was obtained from Victory Element SdnBhd, Malaysia. The mesh size of the PSAC was $8 \times 12$. In the adsorption test, PSAC was used as received without any further treatment. Three types of gases (99.99\% $\mathrm{CH} 4,99.99 \% \mathrm{CO} 2$ and $1 \% \mathrm{H} 2 \mathrm{~S}$, balance $\mathrm{CH} 4$ ) in cylinders supplied by WellgasSdnBhd, Malaysia were used to simulate industrial biogas for the adsorption test.

\subsection{Adsorption Test}

$\mathrm{H} 2 \mathrm{~S}$ adsorption test was carried out using a packed bed reactor test rig as shown in Figure 1. The composition of simulated biogas was adjusted by controlling the flow rate of gases usingAalborg AFC26 mass flow controllers. $\mathrm{CO} 2$ and $\mathrm{CH} 4$ werepassed through a humidification system to give approximately $25 \%$ relative humidity to the biogas inlet stream. H2S/CH4was not passed through the humidification system because $\mathrm{H} 2 \mathrm{~S}$ is soluble in water. The path of the biogas after the humidification system to the reactor is insulated to avoid condensation of moisture. The diameter of the stainless steel tubular reactor used is half inch. The flow rate of the biogas was fixed at $450 \mathrm{~mL} / \mathrm{min}$ with $50 \% \mathrm{CO} 2$, 1000-5000 ppm H2S and balance CH4. This biogas composition was simulated to mimic the data obtained from a collection pond located at FeldaBesout Palm Oill Mill. The height of PSAC was adjusted corresponding to space velocity between 3375 to $13500 \mathrm{~h}-1$ and placed in the middle of the tubular reactor and supported with approximately $0.05 \mathrm{~g}$ glass wool. Adsorption temperature was controlled using a Linberg/Blue $M$ tube furnace.Concentration of $\mathrm{H} 2 \mathrm{~S}$ at the outlet stream was analyzed using anIMR 6000 gas analyzer via electrochemical sensor calibrated for 0-5000 ppm H2S. The workspace of the test rig was ventilated as a safety procedure just in case there is a leakage of hazardous H2S.

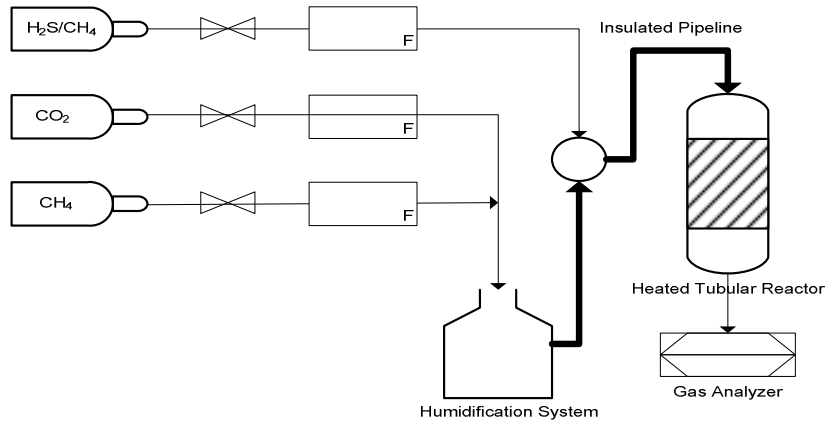

Figure1. H2S adsorption test rig.

\subsection{Characterization}

Several characterizations such as N2 adsorption-desorption, scanning electron microscopy-energy dispersive X-ray spectroscopy (SEM-EDX), thermogravimetric analysis (TGA) and elemental analysis were performed on fresh PSAC and spent PSAC to analyze its surface properties, functional groups and morphologies/composition. N2 adsorptiondesorption was carried out with anMicromeritics ASAP 2020 Surface Area and Porosity Analyzer. Prior to analysis, the samples were degassed for 5 hours. SEM-EDX analysis was carried out by a Quanta FEG 450 at accelerating voltage of $3 \mathrm{kV}$ in order to obtain the sorbent surface morphologies and determine localized chemical composition. TGA was performed using a Perkin Elmer TGA7 with a heating rate of $100 \mathrm{C} / \mathrm{min}$ until $6000 \mathrm{C}$ under a $100 \mathrm{~mL} / \mathrm{min}$ flow of purified air [5]. Elemental analysis was performed using a Perkin Elmer 2400 CHNS Analyzer to analyze the sulfur content of the sample.

\section{RESULTS AND DISCUSSION}

\subsection{Development and analysis of regression model}

In this study, adsorption capacity of activated carbon was determined at breakthrough point, in which theratio of the outlet to inlet $\mathrm{H} 2 \mathrm{~S}$ concentration at 0.05 . The adsorption experimental run was conducted based on thedesign of experiment and the complete design matrix with results are shown in Table 1.

Table1. Design Matrix and Results for Adsorption Capacity At Different Experimental Conditions

\begin{tabular}{|l|l|l|l|l|}
\hline Run Order & $\begin{array}{l}\mathrm{x} 1: \mathrm{H} 2 \mathrm{~S} \text { concentration } \\
(\mathrm{ppm})\end{array}$ & $\begin{array}{l}\mathrm{x} \text { 2: Temperature } \\
(\mathrm{oC})\end{array}$ & $\begin{array}{l}\mathrm{x} \text { 3: Space velocity } \\
(\mathrm{h}-1)\end{array}$ & $\begin{array}{l}\text { y: Adsorption capacity } \\
(\mathrm{mg} / \mathrm{g})\end{array}$ \\
\hline R1 & 3000 & 50 & 3375 & 28.9 \\
\hline R2 & 5000 & 30 & 3375 & 30.3 \\
\hline R3 & 3000 & 50 & 5400 & 21.8 \\
\hline R4 & 3000 & 50 & 5400 & 21.0 \\
\hline
\end{tabular}




\begin{tabular}{|l|l|l|l|l|}
\hline R5 & 1000 & 50 & 5400 & 93.6 \\
\hline R6 & 3000 & 50 & 5400 & 23.0 \\
\hline R7 & 3000 & 70 & 5400 & 18.4 \\
\hline R8 & 3000 & 50 & 5400 & 24.5 \\
\hline R9 & 3000 & 50 & 5400 & 23.0 \\
\hline R10 & 3000 & 50 & 5400 & 22.6 \\
\hline R11 & 5000 & 50 & 5400 & 16.6 \\
\hline R12 & 5000 & 70 & 3375 & 23.9 \\
\hline R13 & 1000 & 70 & 13500 & 5.1 \\
\hline R14 & 1000 & 70 & 3375 & 38.1 \\
\hline R15 & 3000 & 30 & 5400 & 19.1 \\
\hline R16 & 5000 & 30 & 13500 & 1.6 \\
\hline R17 & 1000 & 30 & 3375 & 116.5 \\
\hline R18 & 1000 & 30 & 13500 & 26.1 \\
\hline R19 & 5000 & 70 & 13500 & 3.2 \\
\hline R20 & 3000 & 50 & 13500 & 3.8 \\
\hline
\end{tabular}

Six center points (R3, R4, R6, R8, R9, and R10) are incorporated and spread out in the experimental matrix in order to calculate experimental error and reduce other errors due to unaccounted parameters. Experimental error was calculated to be $4.8 \%$. Using the results shown in Table 1 , adsorption parameters (x1: H2S concentration, $\mathrm{x} 2$ : adsorption temperature and $\mathrm{x} 3$ : space velocity) were correlated with breakthrough adsorption capacity (y) using Design-Expert 6.0.6 software. The model selected by this software is Response Surface Reduced Cubic Model and the equation in coded factors is shown inEq. (2). The graph for the predicted versus actual breakthroughadsorption capacity is shown in Figure2.

$\log 10 \mathrm{y}=1.132-0.423 \times 1+0.005 \times 2-0.438 \times 3+0.228 \times 12-$ $0.081 \times 22-0.111 \times 32$

$+0.174 \times 1 \times 2-0.079 \times 1 \times 3+0.022 \times 2 \times 3-0.129 \times 12 \times 2-$ $0.022 \times 12 \times 3+0.147 \times 1 \times 22$ $+0.078 \times 1 \times 2 \times 3$

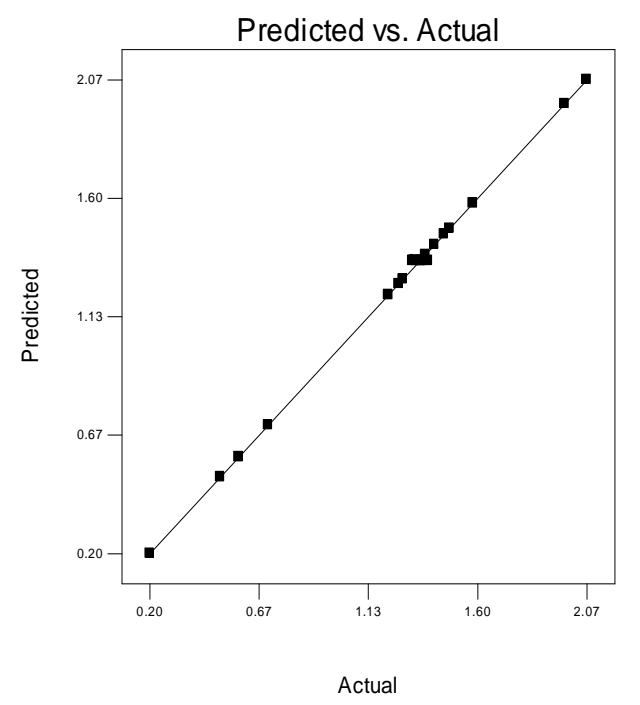

Figure 2.Predicted versus actual log breakthrough adsorption capacity.

The R2 value for Eq. (2) wasfound to be 0.9994 and the predicted R2value of 0.9990 is in reasonable agreement with the adjusted R2value of 0.9980 . On the other hand, adequate precision of 109.0 indicated an adequate signal to noise ratio for the model to be used to navigate the design space. These results verify that the developed model can be used to predict the PSAC breakthrough adsorption capacity within the range of adsorption parameters studied. 
An analysis of variance (ANOVA) that shows the significance of the model and each adsorption parameter is shown in Table 2.Value of Prob> F less than 0.05 indicatesthat model term is significant. Therefore, the model withProb> F value less than 0.0001 implies that the model is significant.The model F-value is 717.7 and there is only a $0.01 \%$ chance that a model F-value this large could occur due to noise. The lack of fit F-value of 0.00 implies the lack of fit is not significant relative to the pure error. There is a $98.70 \%$ chance that a "Lack of Fit F- value" this large could occur due to noise. Non-significant lack of fit indicates that the model fit the experimental result very well. From the ANOVA result, significant terms with high $\mathrm{F}$ value are $\mathrm{x} 1, \mathrm{x} 3$,and $\mathrm{x} 1 \mathrm{x} 2$. Other significant terms with lower $\mathrm{F}$ values are not discussed in this paper because their effect on breakthrough adsorption capacity is less significant as compared to those with higher $\mathrm{F}$ values.

Table2. Analysis of Variance of the Response Surface Reduced Cubic Model

\begin{tabular}{|l|l|l|l|l|l|}
\hline Source & $\begin{array}{l}\text { Sum of } \\
\text { Squares }\end{array}$ & DF & $\begin{array}{l}\text { Mean } \\
\text { Square }\end{array}$ & $\begin{array}{l}\text { F } \\
\text { Value }\end{array}$ & Prob> F \\
\hline Model & 3.89 & 13 & 0.2996 & 717.7 & $<0.0001$ \\
\hline x1 & 0.32 & 1 & 0.3286 & 787.1 & $<0.0001$ \\
\hline x2 & 0.00 & 1 & 0.0000 & 0.1 & 0.7707 \\
\hline x3 & 0.41 & 1 & 0.4124 & 987.8 & $<0.0001$ \\
\hline x12 & 0.11 & 1 & 0.1165 & 279.1 & $<0.0001$ \\
\hline x22 & 0.01 & 1 & 0.0169 & 40.5 & 0.0007 \\
\hline x32 & 0.01 & 1 & 0.0115 & 27.7 & 0.0019 \\
\hline x1x2 & 0.24 & 1 & 0.2427 & 581.3 & $<0.0001$ \\
\hline x1x3 & 0.04 & 1 & 0.0498 & 119.3 & $<0.0001$ \\
\hline x2x3 & 0.00 & 1 & 0.0040 & 9.6 & 0.0210 \\
\hline x12x2 & 0.02 & 1 & 0.0249 & 59.6 & 0.0002 \\
\hline x12x3 & 0.00 & 1 & 0.0008 & 2.0 & 0.2053 \\
\hline x1x22 & 0.03 & 1 & 0.0324 & 77.6 & 0.0001 \\
\hline x1x2x3 & 0.04 & 1 & 0.0492 & 118.0 & $<0.0001$ \\
\hline Residual & 0.00 & 6 & 0.0004 & - & - \\
\hline Lack of Fit & 0.00 & 1 & 0.0000 & 0.0003 & 0.9870 \\
\hline Pure Error & 0.0025 & 5 & 0.0005 & - & - \\
\hline & & & & \\
\hline
\end{tabular}

\subsection{Effect of Significant Terms}

Significant term with highest $\mathrm{F}$ valueis space velocity. Highest $F$ value denotes that space velocity has the greatest effect towards breakthrough adsorption capacity among the adsorption parameters studied.From Table 1, it can be seen that experiments conducted withhigh space velocity $(13500 \mathrm{~h}-$ 1) generally resulted to low breakthrough adsorption capacity. The major reason for this observation is related with the residence time of the biogas in the adsorption zone. At higher space velocity, residence time of biogas in the adsorption zone is shorter. Adsorption studies R13, R16, R19 and R20 that utilized13500 h-1 space velocityshowed lowbreakthrough adsorption capacity,ranging only from $1.6-5.1 \mathrm{mg} / \mathrm{g}$. However, although R18 was also conducted using $13500 \mathrm{~h}-1$ space velocity, but it recorded relatively highbreakthrough adsorption capacity of $26.1 \mathrm{mg} / \mathrm{g}$ that could be mostly attributed to the low H2S concentration used (1000 ppm). When the space velocitywaslowered to $5400 \mathrm{~h}-1$, residence time of the gaswas increased and the PSAC breakthrough adsorption capacity rose significantly to the range 16.6-24.5 $\mathrm{mg} / \mathrm{g}$. Again, R5 that utilized5400 h-1 space velocity achieveda relatively high breakthrough adsorption capacity of $93.6 \mathrm{mg} / \mathrm{g}$ due to the low H2S concentration used (1000 ppm). Further increase inbreakthrough adsorption capacity ranging from $23.9-38.1 \mathrm{mg} / \mathrm{g}$ was obtained when usinglower space velocity of $3375 \mathrm{~h}-1$. Once again, R17 $(116.5 \mathrm{mg} / \mathrm{g})$ is an exceptional case because of the low H2S concentration (1000 ppm). The effect of low H2S concentration will be discussed in the next section. Higher residence time increases the frequency of molecule collision that results to a successful adsorption process [6]. On the contrary, low residence time 
resulted to insufficient time for all $\mathrm{H} 2 \mathrm{~S}$ molecules to adsorb on the PSAC surface. This is especially more prominent when more surface sites are taken up as adsorption process progresses and the remainingH $2 \mathrm{~S}$ molecules have to diffuse deeper into the pores of PSAC.This denotes a longer mean free path for the H2S molecule to travel before it can be adsorbed on the PSAC pore surface. Thus, the finding on the significance of this term provides an insight towards the importance of mass transfer in the adsorption process.

Another significant term with a high $\mathrm{F}$ value of 787.1 is $\mathrm{x} 1$ (H2S concentration). H2S concentration has antagonistic effect towards adsorption capacity, as indicated from a minus sign for the term $\mathrm{x} 1$ in Eq. (2). From the previous discussion onspace velocity, lower H2S concentration resulted to a higherbreakthrough adsorption capacity. Adsorption study using 1000 ppm H2S concentration gives adsorption capacity in the range of $26.1-116.5 \mathrm{mg} / \mathrm{g}$ for run R13 which recorded merely $5.1 \mathrm{mg} / \mathrm{g}$, due to thehigh space velocity used. When using higherH2S concentrationat 5000 ppm, breakthrough adsorption capacity within the range of 1.6 to $30.3 \mathrm{mg} / \mathrm{g}$ was obtained. At higher $\mathrm{H} 2 \mathrm{~S}$ concentration, the diffusion of $\mathrm{H} 2 \mathrm{~S}$ molecules into the pores of PSAC for adsorption to occur is not fast enough to facilitate complete removal of all $\mathrm{H} 2 \mathrm{~S}$ molecules from the gaseous stream. Therefore, the breakthrough occurs faster, i.e., lower adsorption capacity. At lower $\mathrm{H} 2 \mathrm{~S}$ concentration, there will be less $\mathrm{H} 2 \mathrm{~S}$ molecules diffusing into the PSAC pore structure per unit time. Thus on the average, the $\mathrm{H} 2 \mathrm{~S}$ molecule will have a shorter mean free path before reaching an active site due to lower competition with other molecules for adsorption. However, these findings contradict the finding reported by Xue and Liu [7]. Breakthrough capacity was found to increase with higher $\mathrm{H} 2 \mathrm{~S}$ concentration. Nevertheless, it is worthwhile to note that the concentration used in their study was between 210-630 ppm, which is far lower than this study. At very low concentration region, driving force for the $\mathrm{H} 2 \mathrm{~S}$ diffusion will increase with higher concentration and there will be no significant competition for active sites. Therefore, both studies is expected to have different results. In order to have a clearer view on the effect of H2S concentration towards breakthrough adsorption capacity, diffusion coefficient and adsorption rate constant should be obtainedin order todetermine the rate limiting step of this adsorption process.

The effect of temperature (x2)was also investigated in this study.Itwas found to have insignificant effect towards PSAC breakthrough adsorption capacity. However, this does not mean that temperature has no effect onbreakthrough adsorption capacity,but merelydenotes that there is no linear relationship between temperature and adsorption capacity. Based on R16 and R19, increasing temperature increases adsorption capacity. On the contrary, increasing temperature reduces adsorption capacity asobserved from R14 and R17. On the other hand, R7, R8 and R15 show an optimum temperature appearing at $50 \mathrm{oC}$. These three sets of datawereconducted at different concentration and space velocity, indicating that the effect of temperature on breakthrough adsorption capacity is dependent on other parameters. Temperature was found to have significant interaction effect with $\mathrm{H} 2 \mathrm{~S}$ concentrationon breakthrough adsorption capacity as indicated by the high $\mathrm{F}$ value for the term $x 1 \times 2$ (581.4). This significant interaction termcould be used to explain the three sets of data mentioned earlier which also indicates thatthe effect of temperature toward breakthrough adsorption capacity is dependent on the level of $\mathrm{H} 2 \mathrm{~S}$ concentration and space velocity. This finding is again different from those reported in the literature. Xiao et al. studied the effect of temperature and reported that higher temperature reduces adsorption capacity of activated carbon [8]. They explained that physical adsorption is an exothermic process that favors lower temperature.

The synergistic effect of $\mathrm{x} 1 \mathrm{x} 2$ can be visualized inFigure3.From Figure3, increasing temperature at $1000 \mathrm{ppm}$ $\mathrm{H} 2 \mathrm{~S}$ and $3375 \mathrm{~h}-1$ space velocityresulted to a decrease inbreakthrough adsorption capacity. However, whenexperiments were conducted at 5000ppm H2S and 3375 h-1 space velocity, increasing temperature would slightly increase thebreakthrough adsorption capacity. This phenomenon could be due to the extra kinetic energy obtained at higher temperature. This extra kinetic energy affects the diffusion of molecules in the pores and the bulk gas motion in the main stream. At lower $\mathrm{H} 2 \mathrm{~S}$ concentration, the results from the previous section shows that high adsorption capacity can be easily achieved. If temperature is raised, $\mathrm{H} 2 \mathrm{~S}$ molecules will gain extra kinetic energyand therefore reduces the residence time in the adsorbent zone. Shorter residence time does not allow all $\mathrm{H} 2 \mathrm{~S}$ molecules to diffuse deep into the pores especially after most of theouter pores are saturated with $\mathrm{H} 2 \mathrm{~S}$. Thus, more $\mathrm{H} 2 \mathrm{~S}$ molecules will pass through the adsorbent without being adsorb at higher temperature and therefore gives a lower adsorption capacity.However, at higher $\mathrm{H} 2 \mathrm{~S}$ concentration,breakthrough adsorption capacity is generally lower.Therefore, the mean free path for $\mathrm{H} 2 \mathrm{~S}$ diffusion is still considerably low. Higher temperature will improve the diffusion of $\mathrm{H} 2 \mathrm{~S}$ molecules deeper into the pores for adsorption to occur. Although higher temperature will also increase the bulk motion of $\mathrm{H} 2 \mathrm{~S}$ molecules through the adsorbent zone,the positive effect of $\mathrm{H} 2 \mathrm{~S}$ molecule diffusing deeper into the pores of the adsorbent will be more prominent. Thus the adsorption capacity will slightly increase at higher temperature. 


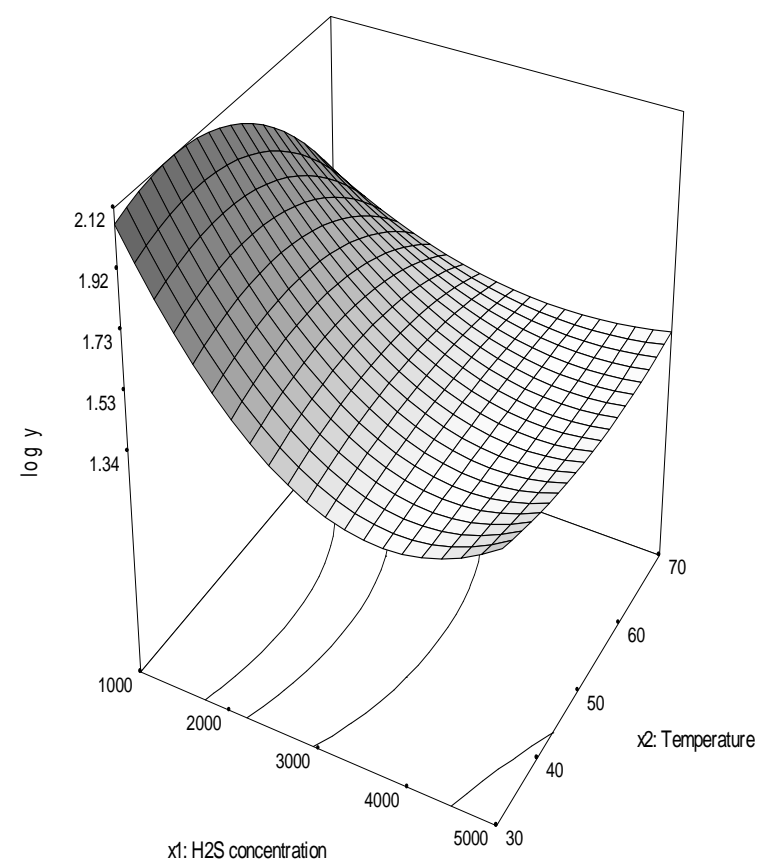

Figure 3. Surface graph of interaction between $1 \times 2$ at $x 3=$ 3375 h-1.

\subsection{Optimization Study}

Using Design Expert Software, optimization was performed in order to search for the highest breakthrough adsorption capacity within the range of parameters studied. Ten sets of solution with predicted breakthrough adsorption capacity were generated and tabulated in Table 3. Set Number 1was identified as the optimum conditions for the adsorption process because it gave the highest predicted breakthrough adsorption capacity. The optimum operating parameters are 1006 ppm H2S, 43.60C and 3926 h-1 space velocity. Three identical experiments were performed using thepredicted parameters and the breakthrough adsorption capacity obtained was $121.9-130.0 \mathrm{mg} / \mathrm{g}$, which verifies the prediction of Design Expert Software. Comparing the result from the optimization process with the Runs in Table 1, H2S concentration has to be kept as low as possible in order to achieve high breakthrough adsorption capacity. However, for practical operation, H2S concentration is generally not consistent and fluctuates significantly depending on the anaerobic digestion condition, unless the digestion is performed in a bioreactor. On the other hand, optimum temperature of $43.60 \mathrm{C}$ on the other hand is beneficial to actual plant operation because trapped biogas from POME anaerobic digestion generally range from 40$500 \mathrm{C}$ due to heating by sunlight. Although in the initial part of this paper, the breakthrough adsorption capacity was found to increase with lower space velocity, but the optimization result shows that there is an optimum value for space velocity.Utilization of lower space velocity does not necessarily guarantee higher breakthrough adsorption capacity. Therefore, for practical application, optimized space velocity should be used in order to obtain higher breakthrough adsorption capacity ofPSAC.

Table3. Prediction of Optimum Adsorption Capacity at Different Conditions

\begin{tabular}{|c|c|c|c|c|}
\hline $\begin{array}{l}\text { Numb } \\
\text { er }\end{array}$ & $\begin{array}{l}\mathrm{H} 2 \mathrm{~S} \\
\text { concentrati } \\
\text { on (ppm) }\end{array}$ & $\begin{array}{l}\text { Tempe } \\
\text { rature } \\
(0 \mathrm{C})\end{array}$ & $\begin{array}{l}\text { Space } \\
\text { Velocit } \\
\text { y (h-1) }\end{array}$ & $\begin{array}{l}\text { adsorption } \\
\text { capacity } \\
(\mathrm{mg} / \mathrm{g})\end{array}$ \\
\hline 1 & 1006 & 43.6 & 3926 & 122.18 \\
\hline 2 & 1000 & 37.3 & 5544 & 109.90 \\
\hline 3 & 1000 & 43.6 & 5792 & 103.27 \\
\hline 4 & 1000 & 30.0 & 5427 & 101.62 \\
\hline 6 & 1000 & 44.1 & 6198 & 97.72 \\
\hline 6 & 1000 & 41.3 & 6729 & 94.84 \\
\hline 7 & 1000 & 57.4 & 3375 & 85.11 \\
\hline 8 & 1000 & 30.0 & 8698 & 68.54 \\
\hline 9 & 1502 & 30.0 & 3375 & 66.98 \\
\hline 10 & 1577 & 30.0 & 3375 & 62.37 \\
\hline
\end{tabular}

\subsection{Characterization of Fresh and Spent PSAC}

The N2 adsorption desorption of fresh PSAC enables the derivation of adsorption and desorption isotherm. Langmuir correlation was found to fit the adsorption capacity of nitrogen at various pressures as shown in Figure 4. Other surface properties analysis were tabulated in Table 4 . Since the t-plot micropore surface area is about $74.2 \%$ of BET surface area for fresh PSAC, it can be concluded that pore structure of PSAC is predominantly micropore $(<2 \mathrm{~nm})$. 


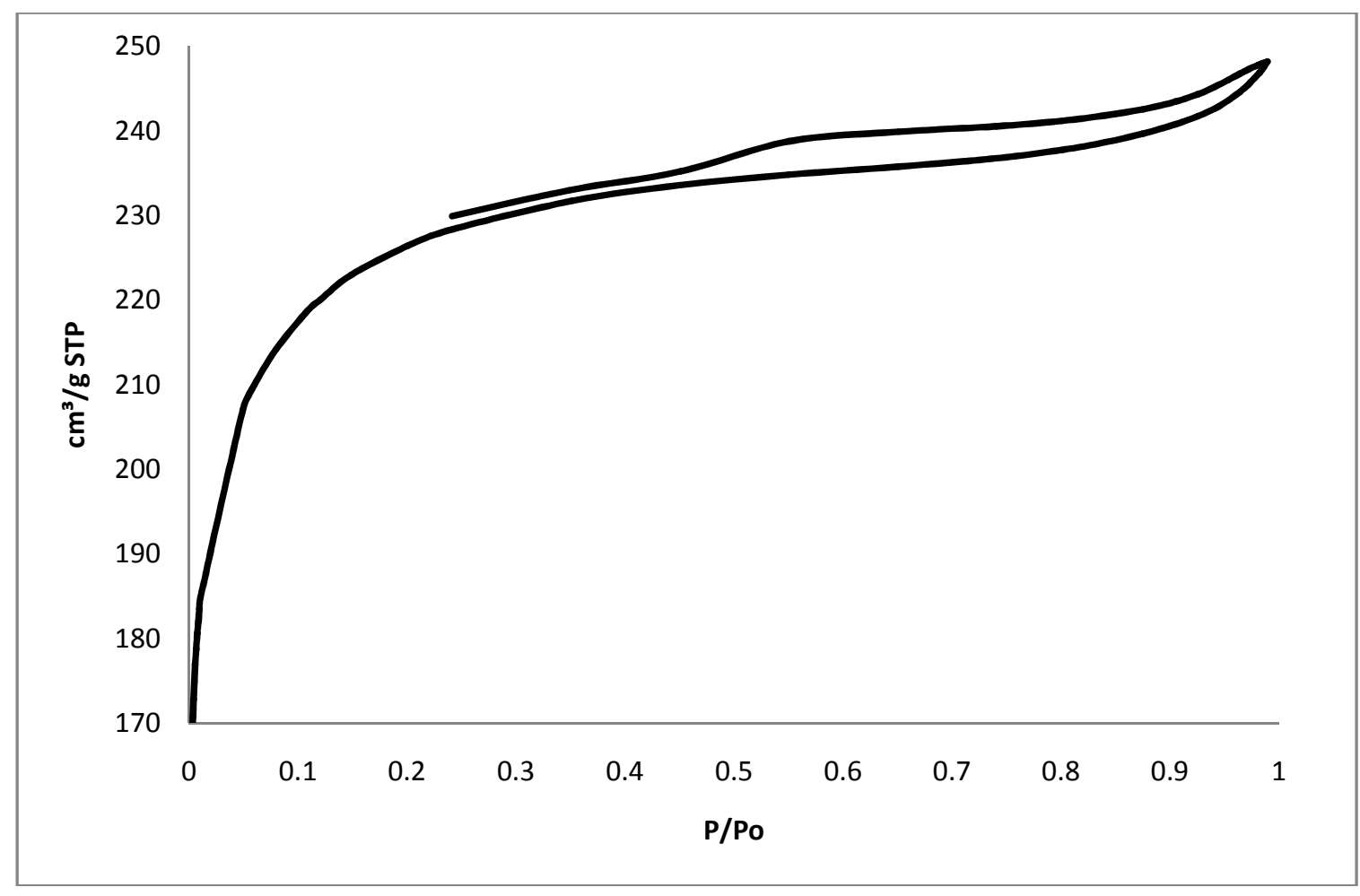

Figure4. N2 adsorption-desorption isotherm of fresh PSAC.

Table4. Characteristic of Fresh PSAC from N2 Adsorption Desorption

\begin{tabular}{|l|l|}
\hline & Fresh PSAC \\
\hline BET surface area $(\mathrm{m} 2 / \mathrm{g})$ & 736.8 \\
\hline Total pore volume $\left(\mathrm{cm}^{3} / \mathrm{g}\right)$ & 0.382 \\
\hline t-plot micropore area $(\mathrm{m} 2 / \mathrm{g})$ & 546.9 \\
\hline $\begin{array}{l}\text { t-plot external surface area } \\
\text { (m2/g) }\end{array}$ & 189.9 \\
\hline \begin{tabular}{l} 
Average pore width $(\AA)$ \\
\hline
\end{tabular} & 20.8 \\
\hline
\end{tabular}

The adsorption of $\mathrm{H} 2 \mathrm{~S}$ and water molecules were determined from the result of Thermal Gravimetric Analysis (TGA).TGA was performed for both fresh and spent PSAC and the results are shown in Figure 5. The derivative form of TGA is also shown in Figure6.The weight of fresh PSAC was reduced rapidly to $80 \%$ when temperature was increased to $1000 \mathrm{C}$. After that, the weight change of fresh PSAC was not significant until $6000 \mathrm{C}$. Spent PSAC, on the other hand, had a weight reduction to $85 \%$ at $1000 \mathrm{C}$, and the second cycle of weight change occurred between 200-4000C. In addition, total weight change of spent PSAC is larger than fresh PSAC within the temperature range of the analysis, denoting spent PSAC contained larger amount of adsorbed substances than fresh PSAC. As shown in Figure 6, fresh PSAC only have one peak formed. Spent PSAC shares the same peak with fresh PSAC but possess additional peak at 200-4000C. The first peak denotes tothe desorption of water molecules. In the H2S adsorption operation, moisture was added to the gas stream because it plays an important role in the adsorption process. Therefore, spent PSAC could contain up to $15 \mathrm{wt} \%$ of moisture, especially due to the long duration of the operation. The second peak of DTG for spent PSAC denotes the release of $\mathrm{SO} 2$ because oxidative atmosphere was used in the analysis [5]. In this study, the peak that denotes to elemental sulfur was not detected at 450-4700C [5], thereforestrengthening the claim that the adsorption of $\mathrm{H} 2 \mathrm{~S}$ was mostly physisorption process. Apart from that, approximately $10 \%$ weight reduction in the 200-4000C region can be used to compare with the adsorption capacity of PSAC $(122.2 \mathrm{mg} / \mathrm{g})$. The value of the adsorption capacity showed that PSAC could adsorb about $12.22 \% \mathrm{H} 2 \mathrm{~S}$. Therefore, if adsorbed $\mathrm{H} 2 \mathrm{~S}$ were removed, weight reduction of PSAC will be $12.22 \%$, which is similar with the results from TGA. This confirms the second peak as $\mathrm{H} 2 \mathrm{~S}$ desorption. 


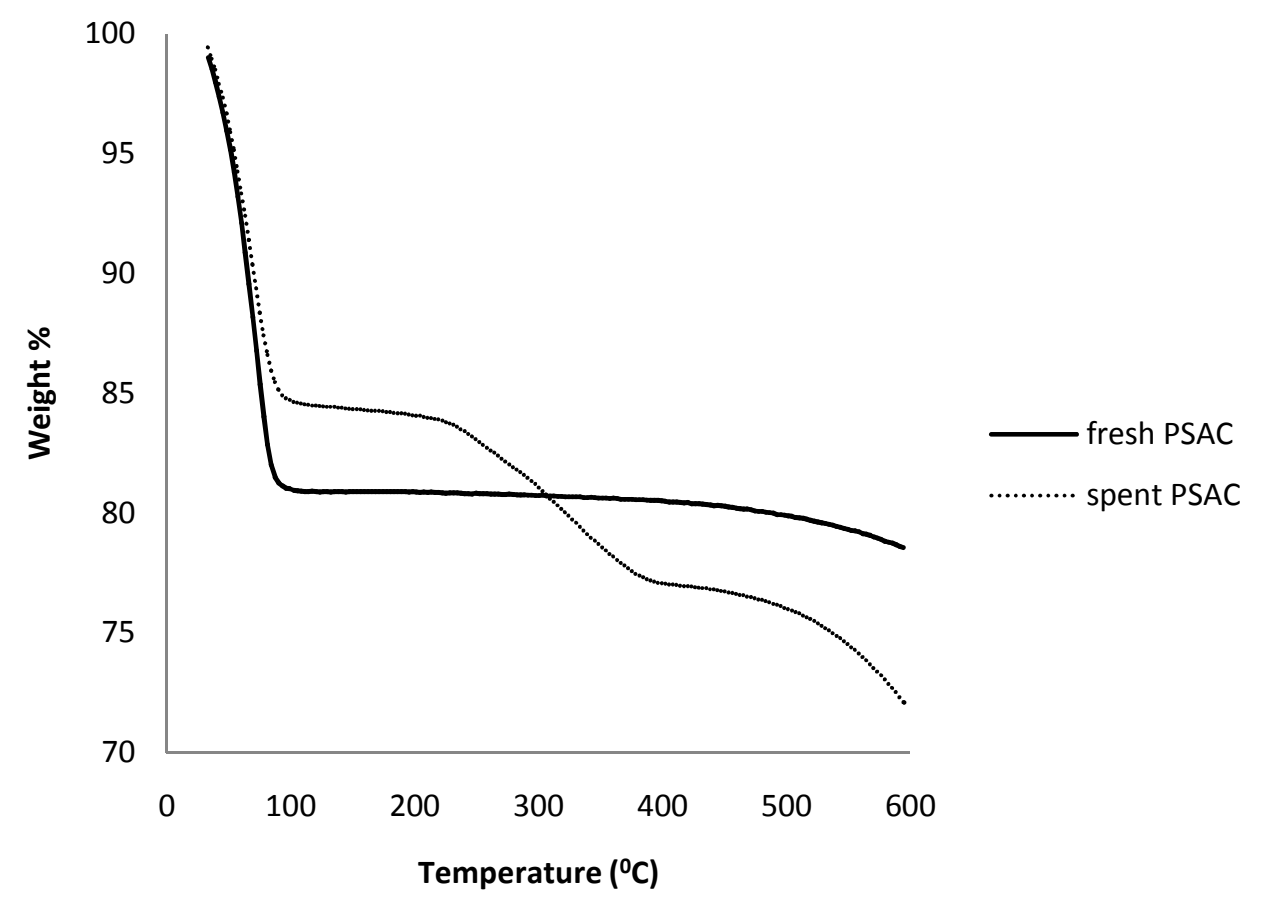

Figure 5.Weight $\%$ versus temperature.

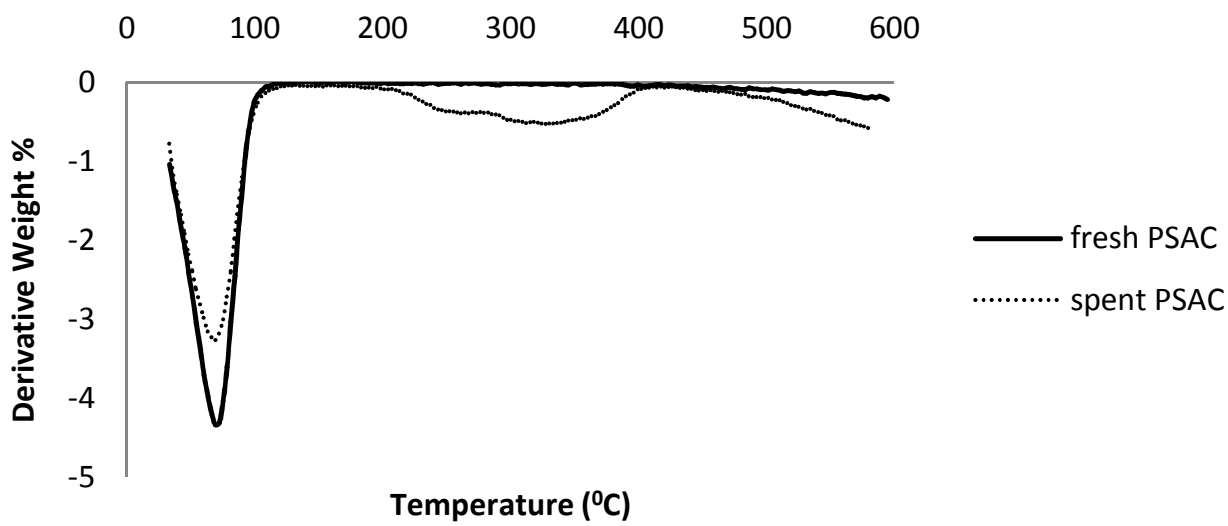

Figure6. DTG curves of fresh and spent PSAC.

Figure 7 and 8 shows the SEM micrographs of fresh and spent PSAC, respectively at various magnifications. The surface of fresh PSAC was found to be cratered. The diameter of the craters is in the magnitude of $30 \mu \mathrm{m}$. Further magnification on the crater shows a porous surface. The pores are generally between $1-2 \mu \mathrm{m}$. This kind of porous structure is the main reason PSAC possesses high surface area, as determined from N2 adsorption desorption analysis. Spent PSAC on the other hand, possess different structure with fresh PSAC. Bone-like structure was found and it is believed to be the product of $\mathrm{H} 2 \mathrm{~S}$ adsorption process. EDX result shows that it contains 3.35\% sulfur, which agree well with a $2.94 \%$ sulfur detected in a CHNS elemental analyzer. Deposit of white agglomerates was also found in fresh and spent PSAC, as shown in Figure 9. The deposit was identified with EDX and it contains about $4 \%$ copper and trace amount of magnesium, potassium, calcium, silicon and iron. This could be the inert remains that did not burn off during the preparation of PSAC from palm shell. The effect of these inert remains towards $\mathrm{H} 2 \mathrm{~S}$ adsorption was not studied. 


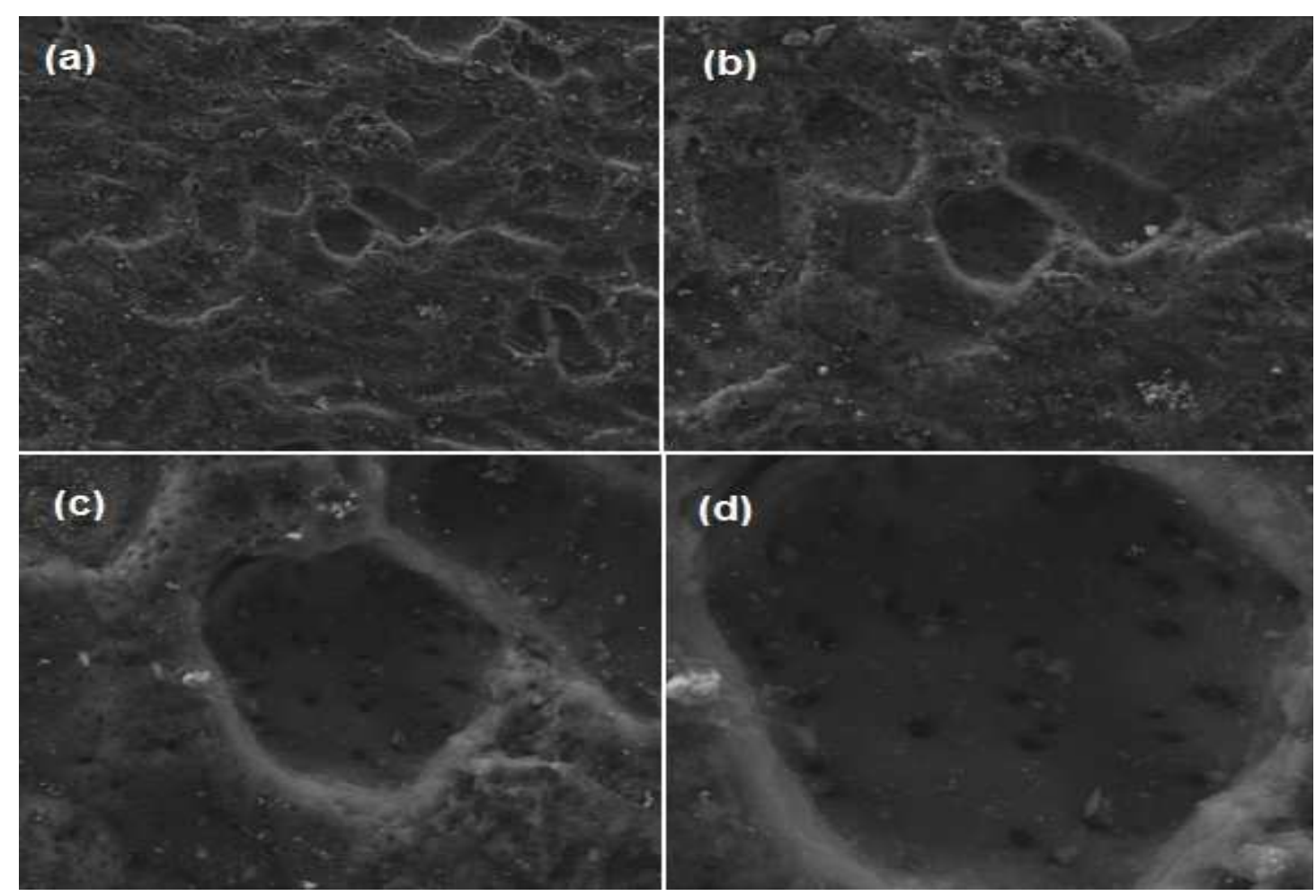

Figure7. SEM of fresh PSAC at various magnifications (a) 1000X, (b) 2000X, (c) 5000X and (d) 10000X.

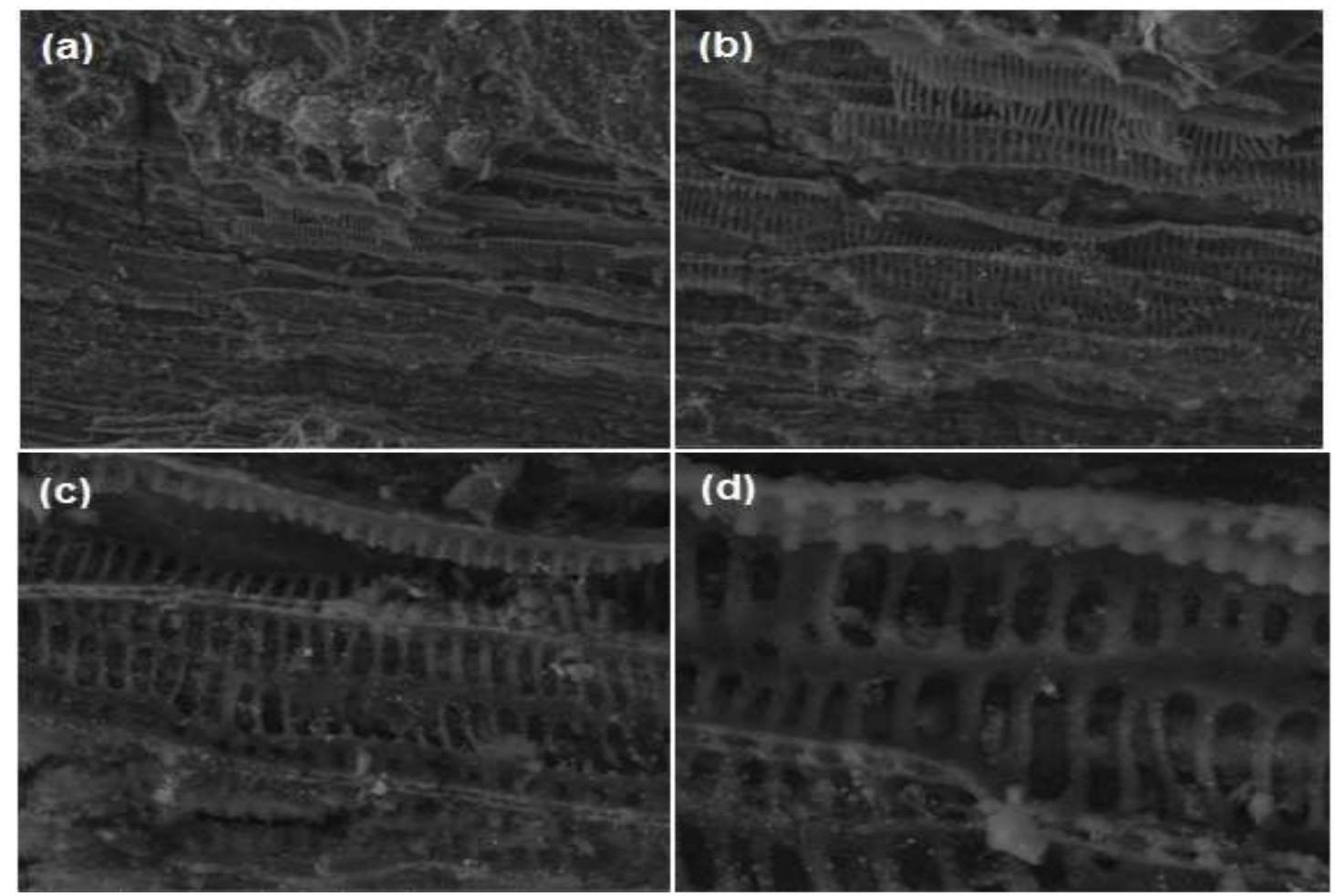

Figure8. SEM of spent PSAC at various magnifications, (a) 1000X, (b) 2000X, (c) 5000X, (d) 10000X. 

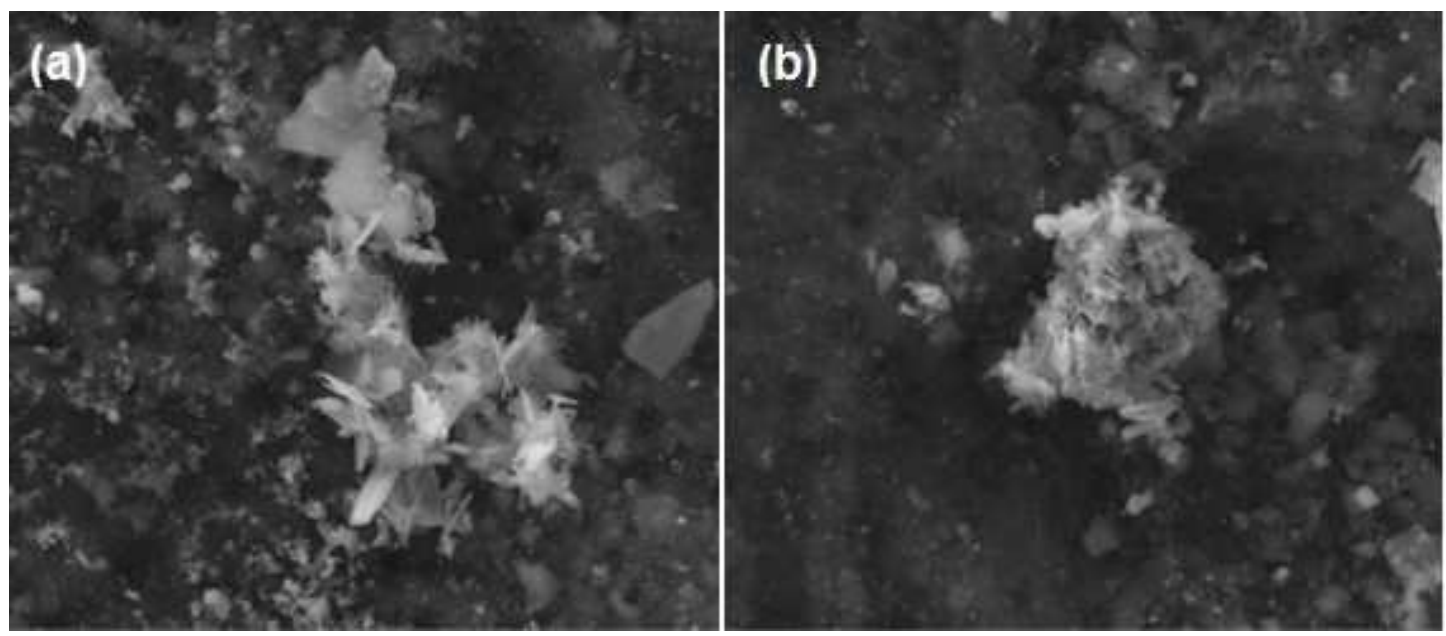

Figure9. Magnification of agglomerates found on the spent PSAC surface.

\section{CONCLUSIONS}

$\mathrm{H} 2 \mathrm{~S}$ adsorption has been successfully performed using palm shell activated carbon. In this study, reaction parameters such as $\mathrm{H} 2 \mathrm{~S}$ concentration, adsorption temperature and space velocity were studied using a statistical analytical method via Design Expert Software. H2S concentration and space velocity were found to be significant in affecting the adsorption capacity, indicated by the generated mathematical model. Interaction terms involving temperature were also found affecting the adsorption capacity. Characterization of fresh and spent PSAC confirm and provide further information on the adsorption of sulfur species on PSAC pore structure.

\section{ACKNOWLEDGMENTS}

This research is financially supported by Program My Brain 15, Knowledge Transfer Program (KTP) Grant No. 6750012 and Research University Postgraduate Research Grant Scheme (RU-PRGS) Grant No. 8045042.

\section{REFERENCES}

[1]Ng, F. Y.; Yew, F. K.;Basiron, Y.; Sundram, K.A renewable future driven with Malaysian palm oil-based green technology.J. Oil Palm Environ.2011, 2, 1-7.

[2]Yacob, S.; Hassan, M. A.; Shirai, Y.; Wakisaka, M.; Subash, S. Baseline study of methane emission from open digesting tanks of palm oil mill effluent treatment. Chemosphere2005,59, 1575-1581.

[3]Pipatmanomai, S.;Kaewluan, S.;Vitidsant, T. Economic assessment of biogas-to-electricity generation system with $\mathrm{H} 2 \mathrm{~S}$ removal by activated carbon in small pig farm. Appl. Energy2009, 86, 669-674.

[4] Wang, L.; Cao, B.; Wang, S.; Yuan, Q. H2S catalytic oxidation on impregnated activated carbon: Experiment and modelling. Chem. Eng. J.2006, 118, 133-139.
[5] Bagreev, A.;Rahman, H.; Bandosz, T. J. Thermal regeneration of a spent activated carbon previously used as hydrogen sulfide adsorbent. Carbon2001, 39, 1319-1326.

[6]Xue, Q.; Liu, Y. Removal of minor concentration of H2S on MDEA-modified SBA-15 for gas purification. J. Ind. Eng. Chem.2012, 18, 169-173.

[7]Xiao, Y.; Wang, S.; Wu, D.; Yuan, Q. Experimental and simulation study of hydrogen sulfide adsorption on impregnated activated carbon under anaerobic conditions. J. Hazard. Mater.2008, 153, 1193-1200.

[8]Maat, H.; Hogendoorn,J.A.;Versteeg, G.F. The removal of hydrogen sulfide from gas streams using an aqueous metal sulfate absorbent, Part I.The absorption of hydrogen sulfide in metal sulfate solutions.Sep. Purif. Technol.2005, 43, 183-197. 